\title{
Article Review for Alteration of Adolescent Self-Efficacy When Applying Brief Counseling at School
}

\author{
Article by Vivian Tawadros \\ School of Behavioral Science, Texila American University, Egypt \\ Email:vtawadros@texilaconnect.com
}

\section{Citation}

A critical review of Rakauskiene, V. \& Dumciene, A. (2013). Alteration of adolescent self efficacy when applying brief counseling at school. Social Behavior \& Personality: an international journal, 41(6), 893-900.

\section{Summary}

This was an empirical quantitative and confirmatory research. The purpose of this study was to show the effect of short-term solution-focused counseling on adolescents' self efficacy, by comparing results of experiment group and comparison group. The research question was: how far can a short-term solution-focused counseling affect adolescent's self-efficacy in issues they face daily at school; such as communication, learning difficulties, emotional problems and changing one's lifestyle, and how long will the impact last? The researchers hypothesized that school seniors who were counseled would have a better self-efficacy which in turn will enhance their self-respect and their ability to deal with personal problems, develop their social skills and boost their self-confidence.

\section{Methodology}

The sample the researchers used was 553 students from the senior class in five different schools. Their age ranged between 15-19. They were divided into an experiment group and a comparison group. The experiment group consisted of 253 adolescents, 139 females and 114 males, while the comparison group was of 300 adolescents, 155 females and 154 males. Each adolescent in the experiment group was counseled in personal problems adolescents thought were more urgent. Counseling sessions were between one and six times within a period of one year. They were recruited randomly from five schools in the Republic of Lithuania during 2011 and 2012. Counseling sessions occurred in the room of the school psychologist, and each session lasted between 50-60 minutes.

\section{Procedures}

In regards to the procedures of the study, during the counseling sessions, participants were asked to evaluate their problem urgency on the General Self-Efficacy Scale (GSE) which consisted of 11 statements on a 4-point scale ranging from 1=totally disagree to $4=$ totally agree. Researchers increased the scale to become an 11-point scale, so evaluators can choose between $0=$ no problem at all and $10=$ extremely serious. In the counseling sessions, each adolescent was counseled according to the urgency of his/her problem.

\section{Results}

The results of pre-test showed that, the severity of problems for both groups was close. Post test measures showed significant improvement in the experiment group. Their problem urgency was significantly lower. Two tables shared showed the pre and post results for both groups. One of the tables indicated that the impact of solution- focused brief counseling was a long term one. 
Evaluation of their problem urgency was measured after 3 months and again after six months. Problem urgency after six months was still lower than before counseling started.

Most adolescents were referred to counseling through an adult; parent or guardian. Only few adolescents sought counseling by themselves, especially when it was psychological counseling. Statistics of the study indicated that most of the problems school seniors sought counseling for were related to communication and relationships whether at school with their peers and teachers, or personal relations.

\section{Critical Reflection}

This is an outdated study. Researchers used strong references related to the topic. However, some references used in this article were comparatively outdated, such as (Gibson-Cline, 1996) and (De Shazer, 1985), in addition to a few in 2000 and 2001. Using these references indicates that the researcher is discussing an old topic and not taking the initiative in choosing this specific topic, specially (De Shazer, 1985) which was used as a reference to the solution-focused brief therapy. Yet, the article introduced a new idea in terms of focusing more on adolescents and their self-efficacy in this short term counseling.

\section{Limitations and Recommendations}

Researcher concluded by mentioning the study limitation and suggesting recommendations to future researchers. Psychologists who conducted the counseling sessions did not have enough experience, neither enough supervision. The researcher mentioned this as a limitation to the study and a recommendation for future studies at the same time. Moreover, another recommendation mentioned was to investigate the impact of adolescents' age and gender on their self-efficacy in solution-based brief counseling. 